\title{
Effect of Scaling and Root Planing on Detection of Tannerella forsythia in Chronic Periodontitis
}

\author{
Ritesh B. Wadhwani, ${ }^{1}$ Minal S. Chaudhary, ${ }^{2}$ Dipti A. Tharani, ${ }^{3}$ and Shweta A. Chandak \\ ${ }^{1}$ Department of Oral Pathology and Microbiology, Saraswati Dhanwantari Dental College and Hospital, \\ Pathri Road, NH 222, Parbhani, Maharashtra 431401, India \\ ${ }^{2}$ Department of Oral Pathology and Microbiology, Datta Meghe Institute of Medical Sciences, \\ Sharad Pawar Dental College, Sawangi, Wardha 442001, India \\ ${ }^{3}$ Department of Dentistry, Government Medical College, Latur 413512, India \\ ${ }^{4}$ Department of Pediatric and Preventive Dentistry, Maitri Dental College, Durg 491001, India
}

Correspondence should be addressed to Ritesh B. Wadhwani; wadhwaniritesh@rediffmail.com

Received 29 August 2013; Revised 6 November 2013; Accepted 28 November 2013

Academic Editor: Atsutoshi Yoshimura

Copyright (c) 2013 Ritesh B. Wadhwani et al. This is an open access article distributed under the Creative Commons Attribution License, which permits unrestricted use, distribution, and reproduction in any medium, provided the original work is properly cited.

\begin{abstract}
Aim. This study was aimed to determine the prevalence of Tannerella forsythia in subgingival plaque samples of chronic periodontitis patients having different level of periodontal destruction and to assess the effect of scaling and root planing (SRP) on prevalence of $T$. forsythia. Materials and Methods. Study included 3 groups: group 1 were healthy individuals, group 2 had periodontitis with probing depth $\leq 5 \mathrm{~mm}$, and group 3 had periodontitis with probing depth $>5 \mathrm{~mm}$. Subjects in groups 2 and 3 exhibited both healthy and diseased periodontal sites. Prevalence of T. forsythia was determined using polymerase chain reaction. Subjects in groups 2 and 3 received SRP and were reevaluated three months after SRP. Results. T. forsythia was not detected in group 1. It was found in diseased sites in $40 \%$ and $73.33 \%$ of patients from groups 2 and 3, respectively. It was also found in healthy sites in $6.67 \%$ and $13.33 \%$ of patients from groups 2 and 3, respectively. The detection frequency of T. forsythia after SRP was $6.67 \%$ and $13.33 \%$ in groups 2 and 3 , respectively. Conclusion. The results indicate a possible association between periodontal disease and presence of T. forsythia. Also, the detection frequency of T. forsythia was reduced after SRP.
\end{abstract}

\section{Introduction}

The term periodontitis refers to an inflammatory disease of the supporting tissues of the teeth caused by specific microorganisms or groups of specific microorganisms resulting in progressive destruction of the periodontal ligament and alveolar bone with pocket formation, recession, or both [1]. Accumulated data indicate that a small group of bacteria are important in periodontal disease exhibiting loss of connective tissue attachment and alveolar bone. Prominent among these are Gram-negative species such as Actinobacillus actinomycetemcomitans, Tannerella forsythia (formerly Bacteroides forsythus or Tannerella forsythensis), Campylobacter rectus, Fusobacterium nucleatum, Prevotella intermedia/nigrescens, Porphyromonas gingivalis, Peptostreptococcus micros, and Streptococcus intermedius [2]. Extensive and convincing data exist for some of these bacteria, so they are considered to be the etiologic agents in periodontitis. These include A. actinomycetemcomitans, T. forsythia, and $P$. gingivalis.

T. forsythia is one of the members of red complex, along with P. gingivalis and T. denticola [3]. T. forsythia is a Gramnegative, strictly anaerobic, and fusiform microorganism. It is known to be present in increased frequency, levels, and proportion in subjects with chronic periodontitis and studies have shown a strong relationship of this bacterium with the clinical parameters considered most meaningful in periodontal diagnosis, namely, pocket depth and bleeding on 
probing [3-5]. The challenges of working with T. forsythia include its fastidious and anaerobic growth requirements for cultural detection [6].

The present study aimed at detecting the frequency of T. forsythia in subjects with chronic periodontitis exhibiting different levels of periodontal destruction using polymerase chain reaction (PCR) based assay. We attempted to correlate the presence of this bacterium with probing depth and gingival status of patients. We further evaluated the effect of scaling and root planing (SRP) on detection frequency of $T$. forsythia.

\section{Materials and Methods}

The present study was carried out at Sharad Pawar Dental College, Sawangi, Wardha, and Dr. Panjabrao Deshmukh Agricultural University, Akola. The subjects included in the study were selected from Outpatient Departments of Periodontics and Oral Diagnosis and Radiology, SPDC, Wardha. All the subjects included in the study signed an informed consent. The study was approved by the Institutional Ethical Committee, Datta Meghe Institute of Medical Sciences, Wardha.

2.1. Subjects. The study was performed on subjects, which were divided into three groups according to their periodontal diagnosis. Group 1: periodontally healthy subjects $(n=10)$, which included 4 men and 6 women with an age range of 25 to 34 years and a mean age of $30.7 \pm 3.02$ years. Group 2: patients having chronic periodontitis with probing depth $\leq$ $5 \mathrm{~mm}(n=15)$, which included 7 men and 8 women with an age range of 33 to 56 years and a mean age of $42.06 \pm 7.25$ years. Group 3: patients having chronic periodontitis with probing depth $>5 \mathrm{~mm}(n=15)$, which included 7 men and 8 women with an age range of 38 to 52 years and a mean age of $45.46 \pm 4.01$ years.

Subjects in groups 2 and 3 exhibited both healthy and diseased periodontal sites and a minimum of three periodontal pockets related to their diagnosis [4]. The criteria for periodontal health (healthy sites) were probing depth $\leq$ $3 \mathrm{~mm}$, gingival index (GI) score $\leq 1$ (Loe and Silness) [7], and absence of bleeding after probing. The criteria for diseased sites were probing depth $>3 \mathrm{~mm}$, high gingival index score $(\mathrm{GI} \geq 2)$, and presence of bleeding after probing.

Exclusion criteria consisted of patients who smoked; patients with dental prostheses; presence of any poorly controlled systemic condition that could have affected the progression of periodontitis; previous periodontal therapy; use of antibiotics in previous three months; subjects with aggressive periodontitis.

Detailed clinical history was recorded and clinical assessments were carried out for the subjects. Subgingival plaque samples were collected and subjected to DNA extraction and subsequent PCR for detection of T. forsythia. After baseline clinical and microbiological assessments, subjects in groups 2 and 3 received full mouth scaling and root planing (SRP). SRP was performed by a periodontist using ultrasonic scaler in single session. Subjects in groups 2 and 3 were reevaluated for clinical parameters and microbiologically for the presence of T. forsythia three months after completion of SRP.

The following clinical parameters were recorded:

(1) gingival index (GI) (Loe and Silness) [7],

(2) bleeding index (Ainamo and Bay) [8],

(3) probing pocket depth (PPD),

(4) clinical attachment level (CAL).

\subsection{Sample Collection}

2.2.1. Group 1. Subgingival plaque sample was collected from at least three periodontal healthy sites (sites having minimum GI score) from healthy individuals. The sampling site was isolated using cotton rolls and supragingival plaque was removed with the help of sterile cotton. The subgingival plaque sample was then collected using sterile Gracey curettes and suspended in microcentrifuge tube containing $500 \mu \mathrm{L}$ of autoclaved TE buffer.

2.2.2. Groups 2 and 3. Subgingival plaque samples were obtained using sterile Gracey curettes from at least three diseased sites (deepest periodontal pockets) and two or more healthy sites of the same subject at baseline. Plaque samples from diseased sites from same subject were pooled, as were those from healthy sites, and placed in two separate microcentrifuge tubes containing $500 \mu \mathrm{L}$ of autoclaved TE buffer. Three months after SRP, plaque samples were collected from the same sites that were labeled as diseased sites at baseline and placed in microcentrifuge tubes containing $500 \mu \mathrm{L}$ of autoclaved TE buffer.

The samples were stored at $-20^{\circ} \mathrm{C}$. The samples were transported under ice packs to the laboratory where extraction of DNA from the plaque samples and subsequent PCR was carried out.

2.3. DNA Extraction. Extraction of DNA from plaque samples was carried out using the method given by Zheng et al. with some modifications [9]. In brief, the samples were centrifuged at $10,000 \mathrm{rpm}$ for 5 minutes at $4^{\circ} \mathrm{C}$ and the supernatant was discarded. $200 \mu \mathrm{L}$ of extraction buffer [ $50 \mathrm{mM}$ Tris- $\mathrm{HCl}$ (pH 8.0), $25 \mathrm{mM}$ EDTA ( $\mathrm{pH} 8.0$ ), and $300 \mathrm{mM}$ $\mathrm{NaCl}, 1 \%$ SDS] was added and the sample was crushed with the help of microtip and the supernatant discarded. $400 \mu \mathrm{L}$ of chloroform was then added to the tube and mixed properly for 1-2 minutes and centrifuged to separate it in two components; the upper aqueous phase containing dissolved DNA was transferred to a fresh microcentrifuge tube. To this $400 \mu \mathrm{L}$ of cold absolute ethanol $\left(-20^{\circ} \mathrm{C}\right)$ was added for the precipitation of DNA. The precipitated DNA was centrifuged to form a pellet at the bottom of the tube, which was then washed twice with 70\% cold ethanol. The pellet of DNA was then suspended in $30 \mu \mathrm{L}$ of autoclaved TE buffer and kept overnight at $4^{\circ} \mathrm{C}$ and subsequently stored at $-20^{\circ} \mathrm{C}$ until PCR was carried out.

2.4. Polymerase Chain Reaction (PCR). The primers (Operon, Germany) used for the detection of T. forsythia consisted of 
TABLE 1: Comparison of mean baseline clinical parameters in three groups.

\begin{tabular}{|c|c|c|c|c|c|}
\hline Clinical parameter & & Group 1 & Group 2 & Group 3 & $F$-value \\
\hline \multirow[t]{2}{*}{ GI Score } & & $0.57 \pm 6.88$ & $1.83 \pm 0.16$ & $1.91 \pm 0.12$ & 362.36 \\
\hline & Dunnett $D$ test & & & $\begin{array}{c}0.00 \\
(P<0.05)\end{array}$ & $\begin{array}{c}0.00 \\
(P<0.05)\end{array}$ \\
\hline \multirow[t]{2}{*}{$\begin{array}{l}\% \text { of sites } \\
\text { with bleeding }\end{array}$} & & $14.28 \pm 2.91$ & $67.21 \pm 7.26$ & $74.61 \pm 3.47$ & 483.55 \\
\hline & Dunnett $D$ test & & & $\begin{array}{c}0.00 \\
(P<0.05)\end{array}$ & $\begin{array}{c}0.00 \\
(P<0.05)\end{array}$ \\
\hline \multirow[t]{2}{*}{ PPD (mm) } & & $2.18 \pm 0.38$ & $4.00 \pm 0.45$ & $5.03 \pm 0.40$ & 142.95 \\
\hline & Dunnett $D$ test & & & $\begin{array}{c}0.00 \\
(P<0.05)\end{array}$ & $\begin{array}{c}0.00 \\
(P<0.05)\end{array}$ \\
\hline \multirow[t]{2}{*}{$\mathrm{CAL}(\mathrm{mm})$} & & $2.04 \pm 0.39$ & $4.71 \pm 0.46$ & $5.35 \pm 0.46$ & 176.17 \\
\hline & Dunnett $D$ test & & & $\begin{array}{c}0.00 \\
(P<0.05)\end{array}$ & $\begin{array}{c}0.00 \\
(P<0.05)\end{array}$ \\
\hline
\end{tabular}

the sequence that encodes T. forsythia $16 \mathrm{~S}$ ribosomal DNA as the target sequence for amplification of the species-specific sequence [10]. The upper (forward) primer, $5^{\prime}$ GCGTATGTAACCTGCCCGCA $3^{\prime}$, is complementary to the sequence 120-139 and the lower (reverse) primer, $5^{\prime}$ TGCTTCAGTGTCAGTTATACCT $3^{\prime}$, is complementary to the sequence 739-760 for T. forsythia. The size of expected PCR product was $641 \mathrm{bp}$.

During PCR, bacterial DNA from the plaque samples was amplified in $25 \mu \mathrm{L}$ of reaction mixture. The reaction mixture consisted of 2X PCR Master Mix (number K0171, MBI Fermentas, USA): $1.25 \mu \mathrm{L}$; upper (forward) primer: $2.5 \mu \mathrm{L}$; lower (reverse) primer: $2.5 \mu \mathrm{L}$; template DNA: $3 \mu \mathrm{L}$; nuclease free water: $4.5 \mu \mathrm{L}$. In addition to the test samples, negative control was used in each set of PCR analysis. The reaction mixture used as a negative control consisted of distilled water instead of the template DNA. The PCR was carried out in a thermal cycler (Gene Amp PCR system 2007, Applied Biosystems) under the following conditions. Initial denaturation step at $95^{\circ} \mathrm{C}$ for 2 minutes, 36 cycles of denaturation at $95^{\circ} \mathrm{C}$ for 30 seconds, annealing at $60^{\circ} \mathrm{C}$ for one minute, extension at $72^{\circ} \mathrm{C}$ for one minute, final elongation step at $72^{\circ} \mathrm{C}$ for 8 minutes, and $4^{\circ} \mathrm{C}$ hold for 30 minutes.

After amplification, PCR products were analysed by horizontal gel electrophoresis carried out using 1.5\% agarose gel. The gel was visualized in a gel documentation system (Bio-Rad) under UV light. The presence or absence of the DNA fragment and its relative size was estimated based on comparison with the DNA marker, which served as a standard.

2.5. Statistical Analysis. The mean values for GI score, percentage of sites with bleeding, PPD, and CAL were calculated for all subjects in a group and then averaged across the group to obtain the mean values for three groups. The differences in clinical parameters at baseline for group 1 and groups 2 and 3 were evaluated by Dunnett's $D$ test. Fisher's exact test was applied to test the difference between the groups for presence of T. forsythia. $Z$ test was used to check whether any difference was found between healthy and diseased sites for the presence of the bacterium in patients from groups 2 and 3. The differences in clinical parameters at baseline and after SRP were tested by applying Student's paired $t$ test. The change in frequency of detecting T. forsythia at baseline and after SRP was checked by Fisher's exact test.

\section{Results}

3.1. Clinical Parameters at Baseline (Table 1). The mean values were calculated for GI score, percentage of sites that exhibited bleeding, PPD, and CAL for each individual in a group and then averaged across the group to obtain the mean values for three groups. There was significant difference in clinical parameters between group 1 and groups 2 and 3 as revealed by Dunnett's test.

3.2. Detection Frequency of T. forsythia at Baseline (Table 2). T. forsythia was detected more frequently from patients with probing depth more than $5 \mathrm{~mm}(73.33 \%)$ as compared to the patients having probing depth up to $5 \mathrm{~mm}(40 \%)$. Fisher's exact test showed a significant difference between groups 2 and 3 for the presence of bacterium. Comparisons within a group by $Z$ test revealed a significant difference between healthy and diseased sites in the same group for the presence of T. forsythia.

3.3. Change in Clinical Parameters in Groups 2 and 3 Three Months after SRP. In group 2, the mean GI score reduced from 1.83 at baseline to 0.82 , after SRP; the mean percentage of sites with bleeding reduced from $67.21 \%$ at baseline to $20.66 \%$, after SRP; the mean PPD reduced from $4 \mathrm{~mm}$ at baseline to $2.97 \mathrm{~mm}$, after SRP; the mean CAL reduced from 4.71 at baseline to $3.56 \mathrm{~mm}$, after SRP. In group 3, the mean GI score reduced from 1.91 at baseline to 0.68 , after SRP; the mean percentage of sites with bleeding reduced from $74.61 \%$ at baseline to $21.96 \%$, after SRP; the mean PPD reduced from $5.03 \mathrm{~mm}$ at baseline to $3.04 \mathrm{~mm}$, after SRP; the mean CAL reduced from 5.35 at baseline to $3.36 \mathrm{~mm}$, after SRP. Student's paired $t$-test showed a significant difference in each of the 
TABLE 2: Detection frequency of T. forsythia in three groups at baseline.

\begin{tabular}{lccc}
\hline \multirow{2}{*}{ Group } & \multicolumn{2}{c}{ Presence of T. forsythia } & $Z$-value \\
& $\mathrm{H}$ & $\mathrm{D}$ & \\
\hline Group 1 & 00 & $\mathrm{NA}$ & $\mathrm{NA}$ \\
Group 2 & $01(6.67 \%)$ & $06(40 \%)$ & $2.33(P<0.05)$ \\
Group 3 & $02(13.33 \%)$ & $11(73.33 \%)$ & $4.17(P<0.05)$ \\
Fisher's exact test & & 0.023 \\
Group 2 versus group 3 & \multicolumn{3}{c}{$(P<0.05)$} \\
\hline
\end{tabular}

H: healthy sites, D: diseased sites, NA: not applicable.

clinical parameter after SRP as compared to baseline for both the groups.

3.4. Detection of T. forsythia in Groups 2 and 3 Three Months after SRP (Table 3). The detection frequency of the bacterium reduced in group 2 from $40 \%$ at baseline to $6.67 \%$ after SRP. The difference was not statistically significant according to Fisher's exact test. In group 3 the value reduced from 73.33\% at baseline to $13.33 \%$ after SRP. The difference was statistically significant.

\section{Discussion}

Amongst the three members of "red" complex, T. forsythia is the least understood microorganism. The seemingly low prevalence of $T$. forsythia in previous studies reflects the extremely fastidious culture requirements and the low sensitivity of culture test system for this microorganism.

In the current study, subgingival plaque samples were obtained from deepest periodontal pockets and the sites that exhibited higher GI score based on the observations that sampling from such sites is likely to enhance the chance of detecting pathogenic bacteria [4]. The plaque samples collected from diseased sites of same individuals were pooled as were the samples obtained from healthy sites. A sample of plaque from a single diseased site may not be representative of the flora of the entire dentition or even of other diseased sites. In general, the greater number of sites that are sampled, the more representative the analysis will be of the overall microbiota profile of the patient [11].

In the present study, none of the samples from healthy controls tested positive for T. forsythia. This is in agreement with results of Klein and Gonçalves [12]. However, few studies report that $T$. forsythia is present in low frequency and levels in healthy subjects. van Winkelhoff et al. detected T. forsythia in $47.9 \%$ sites from control subjects. In their study the gingival condition of sampling sites from control subjects varied between gingival health and various degrees of gingivitis [13], whereas in present study the sites chosen from control subjects were those with no or little inflammation.

The current study showed a higher prevalence of $T$. forsythia in subjects with chronic periodontitis as compared to healthy controls. This is in accordance with previous studies [5, 13-15]. Findings from all such studies have indicated strong association of $T$. forsythia with periodontitis
TABLE 3: Comparison of detection frequency of $T$. forsythia in groups 2 and 3 at baseline and post-SRP.

\begin{tabular}{lcccc}
\hline $\begin{array}{l}\text { T. } \\
\text { forsythia }\end{array}$ & Baseline & Post-SRP & $\begin{array}{c}\text { Fisher's } \\
\text { exact test }\end{array}$ & \\
\hline Group 2 & Present & $06(40 \%)$ & $01(6.67 \%)$ & 0.08 \\
& Absent & $09(60 \%)$ & $14(93.33 \%)$ & $(P>0.05)$ \\
\hline \multirow{2}{*}{ Group 3 } & Present & $11(73.33 \%)$ & $02(13.33 \%)$ & $\begin{array}{c}0.0025 \\
\end{array}$ \\
& Absent & $04(26.67 \%)$ & $13(86.67 \%)$ & $(P<0.05)$ \\
\hline
\end{tabular}

but the exact role of the bacterium in pathogenesis of the disease is not known. However, several virulent factors have been suggested as possible mediators for the disease such as trypsin-like protease [16], sialidase [17], N-benzoyl-valGly-Arg-p-nitroanilide specific protease encoded by the $p r t H$ gene [18], cell surface associated BspA protein [19], S-layerlike proteins [20], and ability to induce apoptosis [21].

The current investigation found an increase in the prevalence of $T$. forsythia with increasing probing pocket depth. Several other investigators also have noted a positive correlation of $T$. forsythia with increasing pocket depth [3-5, $12,22]$. Klein and Gonçalves found the bacterium in $100 \%$ of patients with deeper sites $(>5 \mathrm{~mm})$ and $70 \%$ of patients with shallower pockets (up to $5 \mathrm{~mm}$ ), which is in agreement with this study [12]. The exact reason for increase in frequency of such pathogenic bacteria is not known. However, the following reasons have been suggested for such finding: the higher levels of anaerobiosis at deeper sites, difference in subgingival temperature, and requirement for hemin or other substances, thereby providing a more conducive environment for growth of fastidious and anaerobic microorganisms [22]. This reaffirms the finding that $T$. forsythia, alone or in combination with other microorganisms, may be involved in the process of tissue destruction such as pocket deepening or active attachment loss.

T. forsythia was also found in a limited number of samples in healthy sites from subjects with periodontitis. The bacteria found at healthy sites of diseased subjects might have originated from the infected periodontitis lesions [13]. Differences might exist in virulence of strains within a pathogenic species [23]. Healthy subgingival areas may be colonized by less virulent clones of the pathogenic species [5].

The data from present investigation showed an improvement in clinical parameters in subjects with periodontitis, three months after SRP. These results are consistent with studies in the literature $[24,25]$.

In the current study, SRP was not able to completely remove T. forsythia from subgingival sites. Due to lack of quantification by PCR it was not possible to comment on the after SRP levels of the bacterium. According to previous studies there is reduction in prevalence and levels of $T$. forsythia after SRP [24, 25].

Large numbers of microorganisms are removed from the subgingival area at the time of instrumentation during SRP. It is equally clear that quite large numbers of microorganisms are left behind. According to the literature, within 1 to 2 weeks, the total numbers of bacteria approach the numbers 
that are present in the pocket prior to treatment and then slowly increase over time. By about 3 months most of the sites are recolonized by pretherapy levels of most species. However, studies have shown that the three species of the red complex significantly decreased and other species increased as a result of therapy. This data affirms the role of red complex species in periodontal diseases [25]. If we try to correlate the change in clinical parameters and detection frequency of $T$. forsythia at baseline and after SRP, it is not clear whether a decrease in pocket depth affected colonization by $T$. forsythia or whether a decrease in T. forsythia led to an improved clinical outcome.

The results showed a qualitative difference in the two patient groups regarding the presence of bacterium. No definitive conclusions could be made regarding the quantitative relationship between the study organism and periodontal disease severity. The study detected the prevalence of a single periodontal pathogen. Study of a group of microorganisms and their correlation with clinical parameters could have added more value.

\section{Conclusions}

Thus it is concluded that T. forsythia is strongly associated with chronic periodontitis and its detection frequency positively correlates with probing pocket depth. The bacterium is also present in healthy sites of some patients with chronic periodontitis. Also, the detection frequency of T. forsythia was reduced after SRP.

\section{Conflict of Interests}

There is no conflict of interests regarding the publication of this paper.

\section{Acknowledgments}

The authors wish to thank Dr. V. D. Patil and Dr. N. G. V. Rao, PKV, Akola, India, for allowing to utilize the laboratory facilities and Dr. Mangesh P. Moharil, Assistant Professor at $\mathrm{PKV}$, Akola, India, for guiding in carrying out laboratory procedures.

\section{References}

[1] M. G. Newman, H. H. Takei, and F. A. Carranza, Eds., Carranza's Clinical Periodontology, Saunders, Philadelphia, Pa, USA, 9th edition, 2003.

[2] S. S. Socransky and A. D. Haffajee, "The bacterial etiology of destructive periodontal disease: current concepts," Journal of Periodontology, vol. 63, no. 4, pp. 322-331, 1992.

[3] S. S. Socransky, A. D. Haffajee, M. A. Cugini, C. Smith, and R. L. Kent Jr., "Microbial complexes in subgingival plaque," Journal of Clinical Periodontology, vol. 25, no. 2, pp. 134-144, 1998.

[4] L. A. Christersson, C. L. Fransson, R. G. Dunford, and J. J. Zambon, "Subgingival distribution of periodontal pathogenic microorganisms in adult periodontitis," Journal of Periodontology, vol. 63, no. 5, pp. 418-425, 1992.
[5] A. P. V. Colombo, R. P. Teles, M. C. Torres et al., "Subgingival microbiota of Brazilian subjects with untreated chronic periodontitis," Journal of Periodontology, vol. 73, no. 4, pp. 360-369, 2002.

[6] A. C. R. Tanner and J. Izard, “Tannerella forsythia, a periodontal pathogen entering the genomic era," Periodontology 2000, vol. 42, no. 1, pp. 88-113, 2006.

[7] F. A. Carranza, Ed., Glickman's Clinical Periodontology, vol. 306, WB Saunders, Philadelphia, Pa, USA, 7th edition, 1990.

[8] F. A. Carranza, Ed., Glickman's Clinical Periodontology, vol. 307, WB Saunders, Philadelphia, Pa, USA, 7th edition, 1990.

[9] K. Zheng, P. K. Subudhi, J. Domingo, G. Magpantay, and N. Huang, "Rapid DNA isolation for marker assisted selection in rice breeding," Rice Genetics Newsletter, vol. 12, pp. 255-258, 1995.

[10] A. Ashimoto, C. Chen, I. Bakker, and J. Slots, "Polymerase chain reaction detection of 8 putative periodontal pathogens in subgingival plaque of gingivitis and advanced periodontitis lesions," Oral Microbiology and Immunology, vol. 11, no. 4, pp. 266-273, 1996.

[11] P. M. Loomer, "Microbiological diagnostic testing in the treatment of periodontal diseases," Periodontology 2000, vol. 34, pp. 49-56, 2004.

[12] M. I. Klein and R. B. Gonçalves, "Detection of Tannerella forsythensis (Bacteroides forsythus) and Porphyromonas gingivalis by polymerase chain reaction in subjects with different periodontal status," Journal of Periodontology, vol. 74, no. 6, pp. 798-802, 2003.

[13] A. J. van Winkelhoff, B. G. Loos, W. A. van der Reijden, and U. van der Velden, "Porphyromonas gingivalis, Bacteroides forsythus and other putative periodontal pathogens in subjects with and without periodontal destruction," Journal of Clinical Periodontology, vol. 29, no. 11, pp. 1023-1028, 2002.

[14] A. D. Haffajee, M. A. Cugini, A. Tanner et al., "Subgingival microbiota in healthy, well-maintained elder and periodontitis subjects," Journal of Clinical Periodontology, vol. 25, no. 5, pp. 346-353, 1998.

[15] L. A. Ximénez-Fyvie, A. D. Haffajee, and S. S. Socransky, "Comparison of the microbiota of supra- and subgingival plaque in health and periodontitis," Journal of Clinical Periodontology, vol. 27, no. 9, pp. 648-657, 2000.

[16] A. C. R. Tanner, M. N. Strzempko, C. A. Belsky, and G. A. McKinley, "API ZYM and API An-Ident reactions of fastidious oral gram-negative species," Journal of Clinical Microbiology, vol. 22, no. 3, pp. 333-335, 1985.

[17] B. J. Moncla, P. Braham, and S. L. Hillier, "Sialidase (neuraminidase) activity among gram-negative anaerobic and capnophilic bacteria," Journal of Clinical Microbiology, vol. 28, no. 3, pp. 422-425, 1990.

[18] K. S. Tan, K.-P. Song, and G. Ong, “Bacteroides forsythus prtH genotype in periodontitis patients: occurrence and association with periodontal disease," Journal of Periodontal Research, vol. 36, no. 6, pp. 398-403, 2001.

[19] A. Sharma, S. Inagaki, K. Honma, C. Sfintescu, P. J. Baker, and R. T. Evans, "Tannerella forsythia-induced alveolar bone loss in mice involves leucine-rich-repeat BspA protein," Journal of Dental Research, vol. 84, no. 5, pp. 462-467, 2005.

[20] M. Sabet, S.-W. Lee, R. K. Nauman, T. Sims, and H.-S. Um, "The surface (S-) layer is a virulence factor of Bacteroides forsythus," Microbiology, vol. 149, no. 12, pp. 3617-3627, 2003. 
[21] S. S. Socransky, A. D. Haffajee, C. Smith, and S. Dibart, "Relation of counts of microbial species to clinical status at the sampled site," Journal of Clinical Periodontology, vol. 18, no. 10, pp. 766775, 1991.

[22] G. Dahlén, F. Manji, V. Baelum, and O. Fejerskov, "Putative periodontopathogens in "diseased" and "non-diseased" persons exhibiting poor oral hygiene," Journal of Clinical Periodontology, vol. 19, no. 1, pp. 35-42, 1992.

[23] R. Gmur, J. R. Strub, and B. Guggenheim, "Prevalence of Bacteroides forsythus and Bacteroides gingivalis in subgingival plaque of prosthodontically treated patients on short recall," Journal of Periodontal Research, vol. 24, no. 2, pp. 113-120, 1989.

[24] A. D. Haffajee, "The effect of SRP on the clinical and microbiological parameters of periodontal diseases," Journal of Clinical Periodontology, vol. 24, no. 5, pp. 324-334, 1997.

[25] N. Takamatsu, K. Yano, T. He, M. Umeda, and I. Ishikawa, "Effect of initial periodontal therapy on the frequency of detecting Bacteroides forsythus, Porphyromonas gingivalis, and Actinobacillus actinomycetemcomitans," Journal of Periodontology, vol. 70, no. 6, pp. 574-580, 1999. 


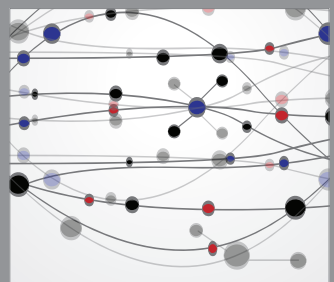

The Scientific World Journal
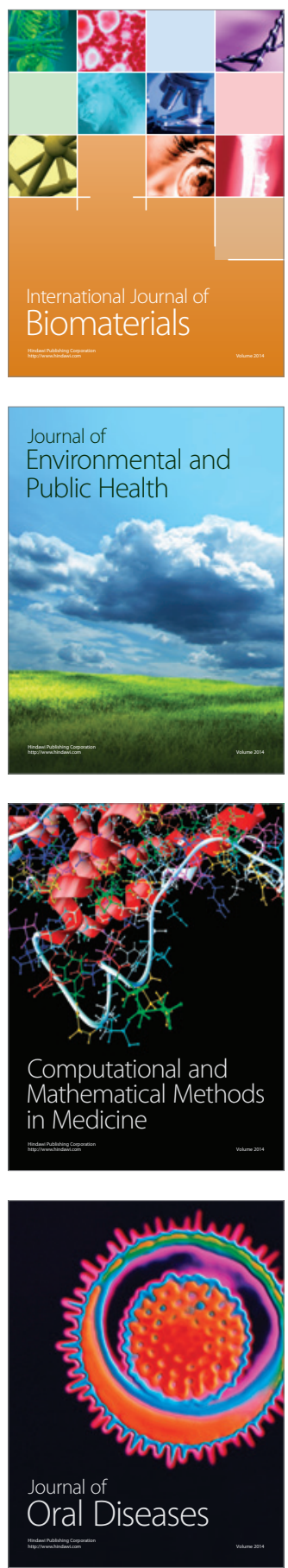
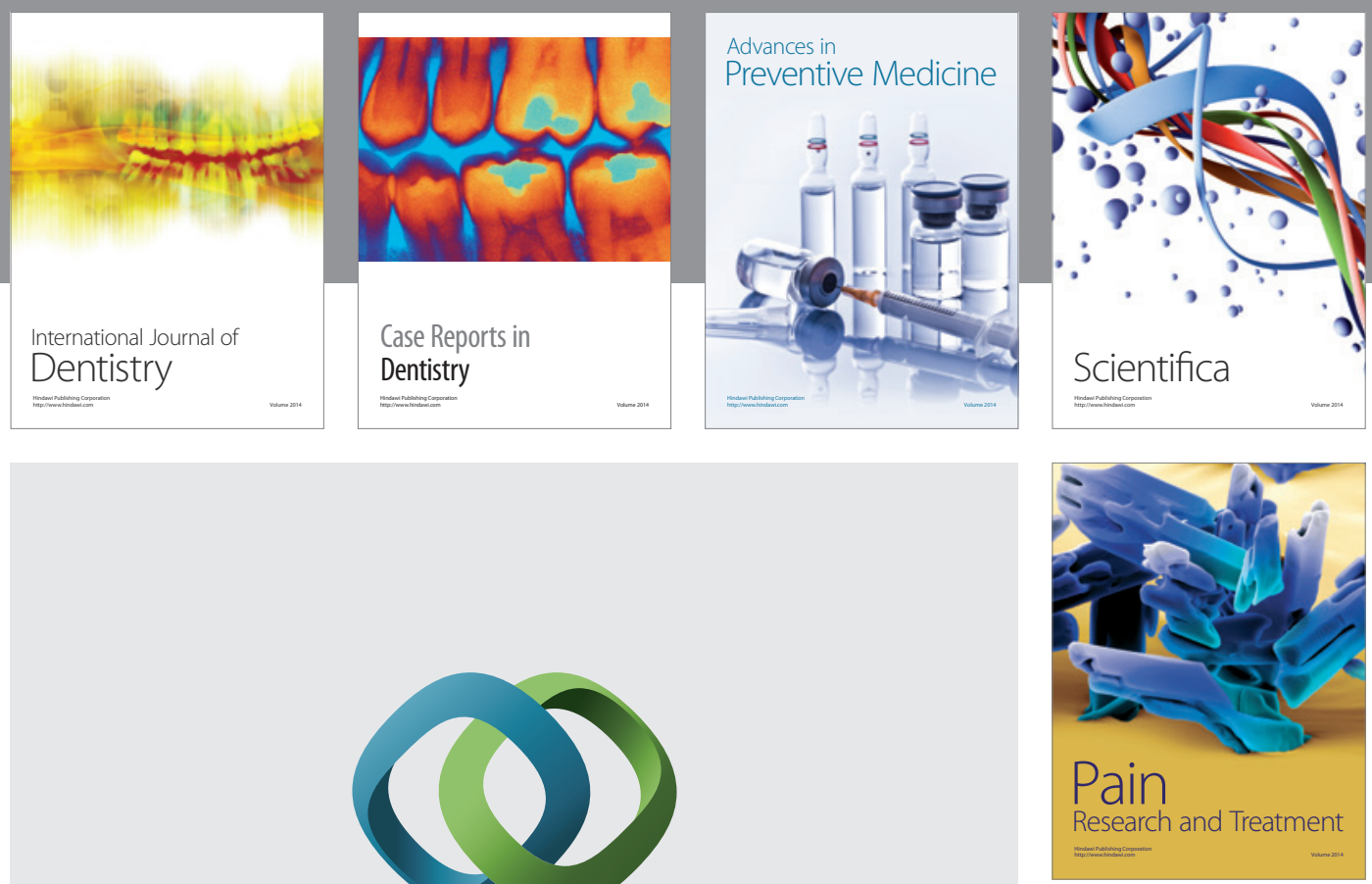

\section{Hindawi}

Submit your manuscripts at

http://www.hindawi.com
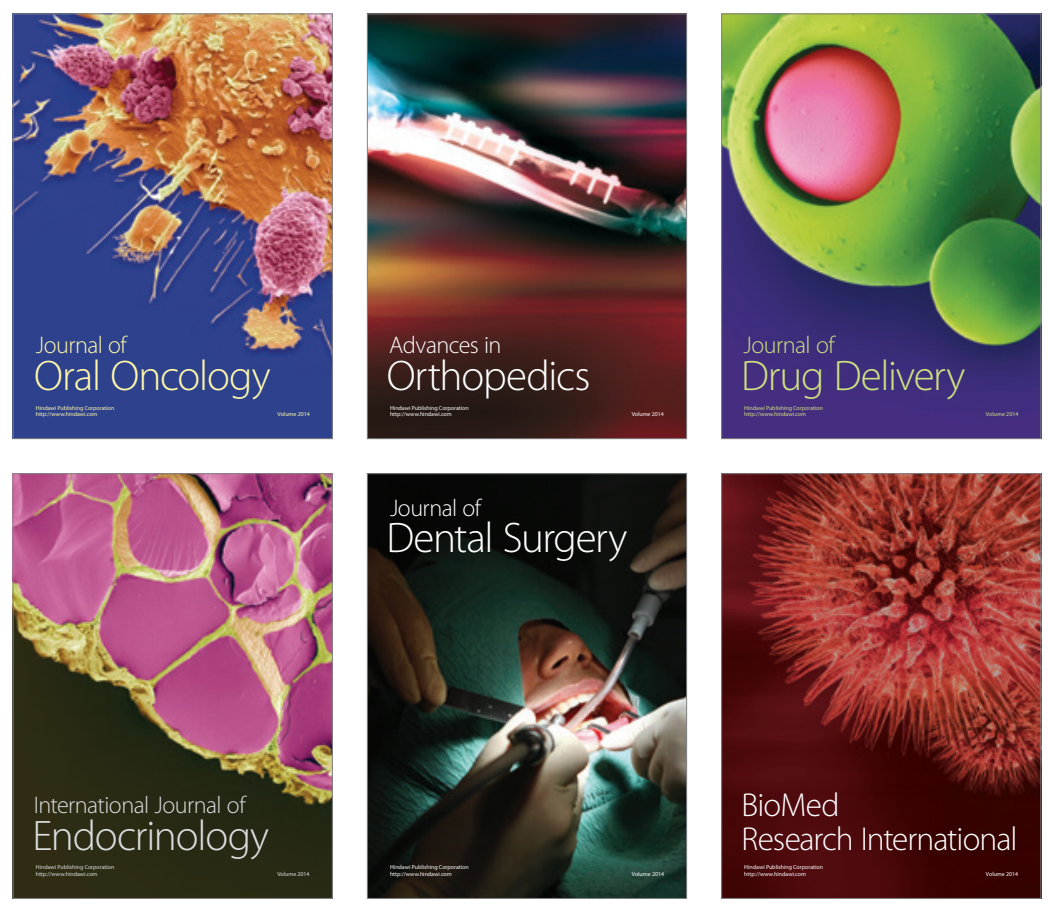

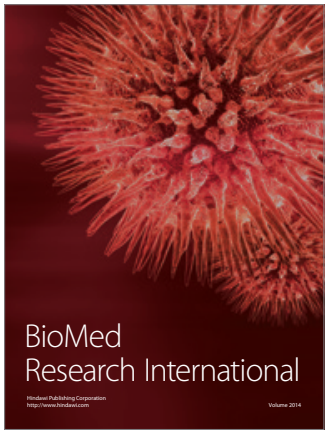

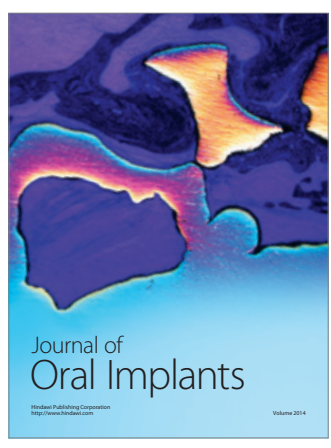
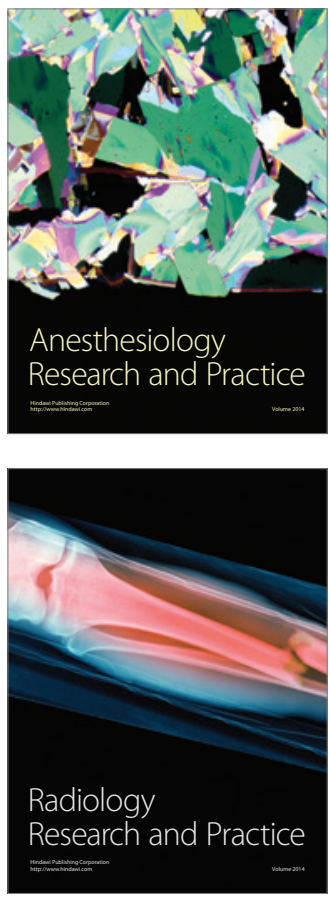